\title{
On the Relationship of the Partial Ring Current to Substorms and the Interplanetary Magnetic Field
}

\author{
C.R. Clauer and R.L. McPherron \\ Institute of Geophysics and Planetary Physics, \\ University of California, Los Angeles, \\ Los Angeles, California, U.S.A.
}

(Received October 17, 1977)

It has been proposed that the symmetric and asymmetric (or partial) ring currents are produced by particles accelerated by substorm processes (DAvis and Parthasarathy, 1967). Recent theoretical work suggests, however, that the convection electric field within the magnetosphere must play an important role in the formation of these magnetospheric current systems. Recent experimental studies have supported this suggestion by correlating the magnetic signatures of these current systems with the electric and magnetic fields of the solar wind. KAMIDE (1974) for example, showed that $D_{S T}$ and the magnetic depression at midlatitudes due to the partial ring current correlate better with the $B_{z}$ component of the interplanetary magnetic field (IMF) than with the $A L$ index. This correlation suggests that the convection electric field produced within the magnetosphere in association with a southward IMF may be a better predictor of ring current strength than is substorm activity. An empirical relation between the solar wind electric field and $D_{S T}$, a measure of symmetric ring current, was developed by BURTON et al. (1975).

The magnetic signatures of the symmetric and partial ring currents are best observed using midlatitude magnetic data. Analysis of data from a world wide chain of midlatitude magnetic observatories allows a quantitative parameterization of a disturbance (ClaUer and MCPHerRon, 1974). Universal time-local time maps of the midlatitude vector magnetic perturbations reveal the temporal and spatial development of the partial ring current and substorm expansion phase current systems. We have used these techniques combined with high-latitude magnetic data and solar wind plasma and magnetic field data to study the association of the partial ring current with substorms and with the solar wind and IMF. An analysis of 25 events shows that the partial ring current magnitude is well correlated with the previous integrated southward IMF and shows little relationship between the partial ring current and substorm magnitude. Of the events examined, 5 showed large partial ring current development associated with clear large southward turnings of the IMF. For each event, when the IMF turned northward decay of the partial ring current to pre-event levels was observed. Other results show a strong correlation between the $A U$ index and the magnitude of the midlatitude minimum which supports the hypothesis that the field-aligned closure of the partial ring current occurs through the eastward electrojet. 
We are indebted to C.T. Russell and M.G. Kivelson for helpful discussions concerning this study. The World Data Center A for Geomagnetism provided the digital ground magnetograms. We thank J. Binsack for the Explorer 33 and 35 plasma data and C.P. Sonett and D.S. Colbrun for the Explorer 33, 35 magnetic field data. This research was supported by ONR Grant \#N00014-75-C0396 with partial support of the computation effort from the Regents of the University of California.

\section{REFERENCES}

Burton, R.K., R.L. MCPherron, and C.T. Russell, An empirical relationship between interplanetary conditions and $D_{S T}, J$. Geophys. Res., 80, 4204-4214, 1975.

Clauer, C.R. and R.L. MCPherron, Mapping the local time-universal time development of magnetospheric substorms using mid-latitude magnetic observations, J. Geophys. Res., 79, 2811-2820, 1974.

Davis, T.N. and R. Parthasarathy, The relationship between polar magnetic activity $D P$ and growth of the geomagnetic ring current, J. Geophys. Res., 72, 5825-5836, 1967.

KAMIDE, Y., Association of $D P$ and $D R$ fields with the interplanetary magnetic variation, J. Geophys. Res., 79, 44-55, 1974. 